\title{
Analisis Bentuk Komunikasi Pada Pagang Gadai Sawah Di Kabupaten Tanah Datar (Studi Kasus Nagari Jaho Kecamatan X Koto)
}

\author{
${ }^{1}$ Benny Oktavian, ${ }^{2}$ Melinda Noer, ${ }^{3}$ Jafrinur \\ ${ }^{123}$ Program Pascasarjana, Universitas Andalas, Indonesia
}

e-mail: bennyoktavian90@gmail.com

\begin{abstract}
Abstrak
Penelitian ini bertujuan menganalisis bentuk komunikasi yang dipakai oleh pemagang dan penggadai dalam melakukan pagang gadai sawah, mengidentifikasi aspek-aspek yang mendasari terjadinya pagang gadai sawah dan menganalisis terjadinya sengketa/konflik komunikasi dalam pagang gadai sawah di Nagari Jaho Kecamatan X Koto Kabupaten Tanah Datar. Penelitian ini telah dilaksanakan di Nagari Jaho, Kecamatan X Koto, Kabupaten Tanah Datar. Pemilihan lokasi penelitian dilakukan secara puposive (sengaja). Masyarakat Nagari Jaho Kecamatan X Koto melakukan pagang gadai karena kebutuhan ekonomi yang mendesak yaitu kebutuhan sekolah anak, kebutuhan sehari-hari seperti kebutuhan dapur dan yang lainnya dan kebutuhan bertani (sawah dan ladang), aspek sosial budaya menjadi hal yang lumrah dalam melakukan pagang gadai. Kehidupan sosial budaya di Nagari Jaho sampai saat ini sangat menjunjung adat istiadat dan mengutamakan musyawarah mufakat dalam hal apapun salah satunya dalam hal pagang gadai. untuk mendekatkan individu satu dengan individu lainnya. Adapun dalam hal pagang gadai juga dilakukan pendekatan secara lansung atau interpersonal descrption dan melakukan musyawarah mufakat dalam menyelesaikan pagang gadai antar kedua belah pihak. Hambatan Komunikasi yang terjadi di Nagari Jaho yaitu sengketa/konflik dalam melakukan pagang gadai adalah keturunan pihak pertama dan pihak kedua tidak diikut sertakan dalam pagang gadai karena beralasan belum cukup umur, jadi akan diberitahukan pada saat umur \pm 17 Tahun dan juga mamak di dalam tatanan adat di Miangkabau khususnya Nagari Jaho tidak melakukan hal-hal yang diluar aturan adat yang ada sehingga menyusahkan keturunan yang ada, fungsi pokok mamak adalah sebagai pengawa harta pusako tinggi (pusaka tinggi) maupun pusako randah (pusako rendah). Penyelesaian sengketa/konnflik yang terjadi dengan cara musyawarah mufakat antar pihak dan yang sudah sampai ke meja hijau harus sesuai hasil dari keputusan yang sudah di ambil secara hukum
\end{abstract}

Keywords: Pagang gadai, Bentuk Komunikasi, Aspek Ekonomi, Sosial Budaya, Sengketa

\section{Abstract}

This study aims to analyze the type of communication used by apprentices and pawners in carrying out pagang gadai, identifying aspects that underlie the occurrence of pagang gadai and analyzing the occurrence of disputes / communication conflicts in pagang gadai in Jaho Village, X Koto Sub District, Tanah Datar District. This research has been carried out in Jaho Village, X Koto Sub District, Tanah Datar District. The selection of research sites was done puposively (deliberately). The people of Jaho Village, X Koto Sub District do pagang gadai because of the urgent economic needs of the children's school needs, daily needs such as kitchen and other needs and farming needs (rice fields and fields), socio-cultural aspects become commonplace in conducting pagang gadai. Socio-cultural life in Jaho Village up to now strongly respects customs and prioritizes consensus in any case, one of which is in the case of a pawn shop to bring one individual closer to another individual. As for the case of pagang gadai 
approach, a direct or interpersonal descrption approach is adopted and a consensus agreement is concluded in completing pagang gadai between the two parties. Communication barriers that occur in Jaho Village, namely disputes / conflicts in conducting pagang gadai are descendants of the first party and the second party is not included in the pagang gadai because they are not old enough, so they will be notified at the age of \pm 17 years and also mamak in the tradition order in Miangkabau especially Nagari Jaho does not do things that are outside the existing customary rules so that it is difficult for the existing descendants, mamak's main function is as a carrier of high pusako (high heirloom) or pusako randah (low pusako). Settlement of disputes / conflicts that occur by means of consensus agreement between parties and those that have reached the court must be in accordance with the results of decisions that have been taken legally.

Kata Kunci : Disputes, Economic Aspects, Forms of Communication, pagang gadai, Socio-Culture.

\section{PENDAHULUAN}

Lahan pertanian merupakan salah satu input penting dalam pembangunan pertanian. Pembangunan pertanian diartikan sebagai langkah berbagai upaya untuk meningkatkan pendapatan petani baik secara fisik maupun nonfisik, membuka lapangan pekerjaa, menentaskan kemiskinan, menumbuhkan ketahanan pangan dan mendorong pertumbuhan ekonomi baik tingkat pusat, aderah maupun tingkat desa (Elsa, 2015). Hal ini menyebabkan lahan pertanian menjadi salah satu media untuk pembangunan pertanian dan keberlansungan hidup petani. Namun Elsa (2015), mengemukakan bahwa fenomena yang sering terjadi adalah berkurangnya lahan garapan petani akibat perubahan fungsi lahan pertanian menjadi lahan non pertanian. Alih fungsi lahan ini seperti pembangunan pemukiman penduduk, industri dan pertokoan serta pembukaan lahan baru. Menurut Febriasi (2014), pagang gadai adalah suatu pembicaraan dimana individu menyerahkan sebidang tanah kepada orang lain dengan perjanjian menerima sejumlah uang dengan syarat dan ketetntuan yang berlaku dan di kembalikan sejumlah yang di pinjam pada saat awal perjanjian.

Pagang gadai di Minangkabau tidak bisa asal dil akukan karena di Minangkabau kepemilikan tanah tidak hanya milik masyarakat petani melainkan juga kepemilikan Adat/Nagari. Pada umumnya tanah di Minangkabau adalah tanah pusako. Menurut Naim (1968) menggadaikan tanah tersebut harus memperoleh dukungan dan kesepakatan dari semua pewaris tanah itu, di samping itu harus pula mendapat persetujuan atau disaksikan oleh penghulu serta pihak-pihak yang dirasa perlu.

Nagari Jaho adalah Nagari yang termasuk kedalam Kecamatan X Koto, Kabupaten Tanah Datar, Sumatera Barat. Kendati termasuk wilayah administratif Tanah Datar namun Nagari Jaho lebih dekat dengan pusat Kota Padangpanjang. Berdasarkan hasil prapenelitian, pagang gadai sawah masyarakat di Nagari Jaho telah berlangsung puluhan tahun yang lalu, hal ini mengakibatkan tradisi tersebut terjadi secara turun temurun dan dilanjutkan oleh para ahli warisnya. Permasalahan yang timbul ketika setelah dilakukannya pagang gadai sawah di Nagari Jaho diantaranya, tidak adanya surat-surat yang mengikat yang jelas atau hitam di atas putih, keabsahan waris, kurang diketahui oleh penghulu kedua belah pihak, tidak jelasnya ulayat, tidak adanya sepengetahuan yang terkait atau di bawah tangan, dan tidak diketahui batas/jihad (utara, barat, timur, dan selatan) yang mengakibatkan terjadi salah paham atau sengketa/konflik pada ahli waris untuk menebus pagang gadai padi sawah orang tua mereka dahulu. Dalam hal tersebut terjadi kesalahpahaman komunikasi antara ahli waris yang ingin menebus tanah orang tuanya kembali.

Tujuan penelitian (1) menganalisis bentuk-bentuk komunikasi yang dipakai oleh pemagang dan penggadai dalam melakukan pagang gadai sawah di Nagari Jaho Kecamatan X Koto Kabupaten Tanah 
Datar; (2) mengidentifikasi aspek-aspek yang mendasari terjadinya pagang gadai sawah di Nagari Jaho Kecamatan X Koto Kabupaten Tanah Datar; (3) menganalisis terjadinya sengketa atau konflik yang terjadi pada pagang gadai sawah di Nagari Jaho Kecamatan X Koto Kabupaten Tanah Datar

\section{METODE}

Penelitian ini menggunakan metode deskriptif dengan pendekatan kualitatif yaitu menggambarkan dengan jelas bagaimana sistem komunikasi pagang gadai yang terjadi di Nagari Jaho. Menurut Sugiyono (2001), Snowball sampling adalah teknik penentuan sampel yang mula-mula jumlahnya kecil, kemudian sampel ini disuruh memilih teman-temannya untuk dijadikan sampel begitu seterusnya, sehingga jumlah sampel semakin banyak. Ibarat bola salju yang menggelinding semakin lama semakin besar. Pada penelitian ini informasi yang diberikan oleh informan kunci merupakan informasi yang sangat berharga karena dari informan tersebut penelitian ini akan bermula. Penentuan sampel pertama pada penelitian ini dilakukan secara acak (random sampling).

Pemilihan pendekatan kualitatif pada penelitian ini karena peneliti ingin mengetahui dan memahami bagaimana analisis sistem komunikasi pagang gadai sawah yang telah dilakukan di Nagari Jaho Kecamatan X Koto. Kriyantono (2008) menambahkan, penelitian kualitatif bertujuan untuk mendeskripsikan fenomena-fenomena sosial di masyarakat melalui data-data yang dikumpulkan kemudian dianalisa secara mendalam untuk menemukan jawaban. Penelitian ini lebih menekankan pada persoalan kedalaman data bukan pada banyaknya data.

Analisis data adalah proses mencari dan menyusun secara sistematis data yang diperoleh dari hasil wawancara, pengamatan aktif, catatan lapangan dan dokumentasi. Pengoganisasian data dilakukan dalam kategori tertentu, menjabarkannya kedalam unit-unit, melakukan sintesa, menyusun kedalam pola, memilih mana yang penting dan yang akan dipelajari serta membuat kesimpulan. Sehingga mudah dipahami oleh diri sendiri dan orang lain (Sugiyono, 2012).

Meleong (2010) menyatakan bahwa Analisis data kualitatif berlangsung dengan proses sebagai berikut: 1) mencatat data lapangan dengan pengkodean tertentu agar sumber data tetap dapat ditelusuri;2) mengumpul, memilah milah, mengklasifikasikan, mensintesiskan, membuat ikhtisae dan membuat indeksnya; 3) berfikir agar ketegori data itu bermakna, mencari dan menemukan pola dan hubunganhubungan, dan membuat temuan-temuan umum.

Pada Penelitian ini, analisis data mengikuti teknik yang dianjurkan oleh Sugiyono di atas, yaitu :

Tujuan Pertama

Tujuan pertama penelitian ini adalah mendeskripsikan dan menganalisa Bentuk komunikasi yang dipakai dalam melakukan pagang gadai di Nagari Jaho Kabupaten Tanah Datar data sekunder berupa jumlah lahan pertanian Sawah dan pemilik lahan pertanian sawah akan dianalisis dan ditafsirkan Dalam pengertian deskriptif kualitatif.

Tujuan Kedua

Tujuan Kedua penelitian ini mengidentifikasi aspek-aspek apa yang mendasari terjadinya Pagang gadai di Nagari Jaho Kabupaten Tanah Datar. Maka, data yang telah diperoleh dari hasil wawancara langsung dengan penghulu, wali nagari dan sesepuh/yang dituakan akan dianalisis dan ditafsirkan dalam pengertian deskripti kualitatif.

Tujuan Ketiga

Tujuan Ketiga penelitian ini adalah mengetahui bentuk dan penyebab terjadinya ingkar komunikasi dalam pagang gadai di Nagari Jaho Kabupaten Tanah Datar. Maka, data yang telah diperoleh dari hasil wawancara langsung dengan penghulu, wali nagari dan sesepuh/yang dituakan serta 
data sekunder berupa data jumlah lahan pertanian sawah akan dianalisa dan ditafsirkan dalam pengertian deskriptif kualitatif.

\section{HASIL DAN PEMBAHASAN}

\subsection{Bentuk Komunikasi Pagang gadai Sawah di Nagari Jaho Kecamatan X Koto Kabupaten Tanah Datar}

Bentuk Komunikasi yang dipakai di Nagari Jaho Kecamatan X Koto Kabupaten Tanah Datar tersebut menggunakan komunikasi secara langsung sebagai alat untuk memperlancar maksud mereka, yaitu dengan bertatap muka secara langsung antara sipemagang dan sipenggadai atau tidak langsung dengan menggunakan surat bertuliskan perjanjian pitih diganti pitih tabilang (uang diganti uang terbilang), tanah diganti tanah, sawah diganti sawah dan emas diganti emas, untuk melakukan transaksi pagang gadai, karena sipemagang memberikan pinjaman ataupun uang untuk keperluan sipenggadai, adapun hal lain yang terjadi dalam melakukan pagagang gadai di Nagari Jaho dengan memakai orang ketiga dalam melakukan transaksi pagang gadai. Dalam hal komunikasi di Nagari jaho sipemagang dan sipenggadai menggudnakan alat tulis seperti pulpen dan kertas untuk mencatat perjanjian yang mereka lakukan dan disaksikan oleh pihak-pihak yang terkait dari pemerintah desa, niniak mamak, saksi dll. Hal senada juga disampaikan oleh Nurudin (2004) bahwasanya semua yang dilakukan oleh pelaku pagang gadai mmenemukan kata sepakat dalam transaki pagang gadai mereka baik berupa lisan, tulisan maupun bertukar ide dalam menjalin kesepakatan itu adalah bentuk dalam suatu sistem komunikasi yang dasar dalam komunikasi menjadi sumber informasi.

Bentuk komunikasi di Nagari Jaho Kecamatan X Koto Kabupaten Tanah Datar dalam pagang gadai lahan pertanian adalah bentuk komunikasi komunikasi antarpribadi (interpersonal communication), yaitu komunikasi yang berlangsung secara dialogis antara dua orang atau lebih antara sipemagang dan sipenggadai. Menurut Effendy (1993) komunikasi antarpribadi (interpersonal communication), yaitu komunikasi yang dilakukan satu atau dua orang lebih. Karakteristik komunikasi antar pribadi yaitu: dimulai dari diri sendiri. sifatnya transaksional karena berlangsung serempak. komunikasi yang dilakukan tidak hanya mencakup aspek-aspek isi pesan yang dipertukarkan, tetapi juga meliputi hubungan antar pribadi. adanya kedekatan antara pihak-pihak yang berkomunikasi, adanya saling ketergantungan atau tolong menolong antar pihak-pihak yang berkomunikasi dan tidak dapat diubah maupun diulang.

\subsection{Aspek-aspek yang menyebabkan terjadinya Pagang Gadai sawah di Nagari Jaho Kecamatan X Koto Kabupaten Tanah Datar}

\section{1) Ekonomi}

Masyarakat Nagari Jaho Kecamatan X Koto melakukan pagang gadai karena kebutuhan ekonomi yang mendesak yaitu kebutuhan sekolah anak, kebutuhan sehari-hari seperti kebutuhan dapur dan yang lainnya dan kebutuhan bertani (sawah dan ladang).

Kebutuhan ekonomi di tengah-tengah masyarakat Nagari Jaho Kecamatan X Koto adalah untuk menyambung hidup dari segi ekonomi dan tidak menurunkan derajat sosial di tengah-tengah masyarakat lainnya, karena mempengaruhi hidup bermasyarakat di Nagari Jaho tersebut, hal senada disampaikan oleh Lincolyn (1992) bahwa Kebutuhan ekonomi adalah dasar untuk menjalani hidup yang baik di tengahtengah masyarakat agar dipandang oleh masyarakat lainnya.

Selain itu kesulitan ekonomi di Nagari Jaho yang dimaksudkan adalah kesulitan untuk mendapatkan pinjaman tanpa menjual sawah sipeminjam yang menjadi awal munculnya idea atau gagasan atau niatan untuk menggadaikan sawah kepada individu yang mempunyyai harta berlebih (Sodirah, 1998). 
Masyarakat menggadaikan sawah ada yang sekali meminjam dan ada juga bertahap meminjamnnya karena didesak kebutuhan lainnya namun beberapa sipemagang ada yang mau dan ada yang tidak untuk peminjaman secara bertahap .

\section{2) Sosial Budaya}

Masyarakat Minangkabau tradisonal, pagang gadai atau pegang gadai merupakan kebiasaan yang telah dimapankan atau disepakati dalam adatnya. Pada hakikatnya pagang gadai merupakan salah satu bentuk pengalihan property, terutama tanah, disamping melalui pewarisan, jual beli, hibah, pemberian dan wasiat yang dikenal dalam masyarakat Minangkabau, Berger (1982) mengemukakan tentang kontruksi realitas sosial, adat Minangkabau dikonstruksi melalui dari luar,dalam dan objek. Dengan logika diatas, juga adat salingka Nagari menjadi relevan untuk di pahami. Adat salingka (selingkar) Nagari, ini berarti tiap-tiap Nagari berdiri sendiri dengan adatnya dan otonom. Persyaratan fisik suatu Nagari adalah (1) basosok bajurami (perbatasan), Nagari harus mempunyai batas-batas ke Nagarian yang jelas yang diakui oleh baik tingkat desa maupun tingkat pemerintahan, (2) balabuah batapian, Nagari harus mempunyai jalan lingkungan taua jalan umum dan jalan penghubung antar Nagari serta tapian tempat mandi atau tempat pemandian untuk masyarakat, (3) barumah batanggo, mempunyai rumah tangga (tempat tinggal) menandakan bahwasanya individu tersebut memang lahir dan tumbuh besar di Nagari tersebut, (4) bakorong bakampung, mempunyai tali yang menghubungkan suatu kelompok dengan kelompok lainnya untuk menopang keberlansungan hidup, (5) basawah baladang, mempunyai daerah persawahan dan perladangan untuk keberlansungan hidup, (6) babalai bamusajik, mempunyai balai adat tempat musyawarah dalam hal apapun dan mesjid tempat ibadah dan kegiatan keagamaan (7) bapandam bapakuburan, mengatur masalah kematian dan upacaranya yang sesuai dengan adat istiadat setempat dan mempunyai pusara tempat berkubur atau ada tanah untuk tempat menguburkan anggota keluarga menandakan bahwasanya individu emamng orang setempat secara turun temurun (Amir, 1999).

Adat Minangkabau dapat dibagi menjadi : adat yang sabana adat, adat yang diadatkan, adat yang taradat dan adat istiadat (Navis, 1986; Latif 2002). adat yang sabana adat (Adat yang sebenar adat) adalah nilai-nilai hakiki yang menjadi pedoman hidup berupa Sunnatullah, Al-quran, Hadis dan hukum alam, merupakan sesuatu yang tidak dapat berubah tasa dasar apapun, Adapun di Nagari Jaho masih menanamkan nilai-nilai ini terbukti dengan kegiatan anak nagari didikan subuh, magrib magaji (maghrib mengaji) serta kegiatan keagaaman lainnya. adat yang diadatkan (Adat yang diadatkan) merupakan adat yang diterima dari dasar atau awal adat di Minangkabau atau adat nenek moyang dan akan tetap dipakai juga dipertahankan secara turun temurun tanpa melanggar norma-norma keagamaan seperti ceramah tiap malam jum'at oleh mubaligh cilik maupun penceramah yang di datangkan dari luar daerah. Di Nagari Jaho masih menerpakan jugak pepatah seperti : adat basandi sara' (adat bersandi syarak), sara' basandi kitabullah yaitu al-qur'an dan al-hadist (syarak bersandi kitabullah), hidup komunal, matrilinial (menurut garis keturunan wanita/ibu/mandeh, soko dan pusako. adat yang taradat (Adat yang taradat) adalah kesepakatan di Nagari, suku dan kampung yang berkaitan dengan kepentingan bersama setelah di musyawarah dan mufakat. Sedangkan adat istiadat adalah suatu kebiasaan atau yang sudah menjadi tradisi pada suatu Nagari yang sudah di jalankan turun temurun oleh Nagari tersebut.

Masyarakat Minangkabau adalah masyarakat yang hidup bersama, bergolong-golongan dan berkelompok-kelompok (bersuku-suku) yang beragam dengan sistem kekerabatan matrilinial (berdasarkan garis keturunan ibu) baik secara umum maupun secara khusus hal itu dibuktikan tiap daerah di Minangkabau mempunyai adat istiadat yang berbeda dan mempunyai khas tersendiri tiap daerahnya namun beda dengan hal pagang gadai hamper sama secara hukum adat maupun hukum pemerintah. Landasan sistem kekerabatan di Minangkabau adalah anak dipangku (keluarga inti) darah kerutunan, kamanakan dibimbing (keluarga besar) keturunan dari orang tua perempuan dahulu, orang kampung dipatenggangan (bermasyarakat) memandang masyarakat lainnya. Kekerabatan ini merupakan hubungan 
emosional dengan kepedulian terhadap etnis, hubungan orang tua dengan anak, hubungan dengan kamakanakan (anak saudara perempuan), sebagai urang sumando, keluarga ayah, para besan, induk bako anak pisang (keturunan dari laki-laki) serta dengan orang kampung dan masyarakat lainnya.

Sistem kekerabatan di Minangkabau Seseorang anak keturunan perempuan akan menerima warisan dari mande (ibu) dan mande (ibu) menerima warisan dari nenek (tuo/anduang/buyuik/inyiak) dan yang senenek disebut sajurai dan orang-orang yang seibu disebut saparuik warisan yang ada adalah warisan turun temurun yang sedarah (Amir, 1999) dan orang tua dulu mendapatkan harta dari kepala suku yang mana tujuan dari kepala suku adalah untuk membantu individu lain untuk ke berlansungan hidup individu tersebut dan mendapat status sosial di tengah masyarakt lainnya dan juga hal tersebut juga terjadi di Nagari Jaho seperti mak hindun, beliau mendapatkan harta dari orang tua terdahalu yang disebut inyiak/biyai pesan yang disampaikan oleh orang tua beliau dahulu :

"harato den tinggan untuak kau jo katurunan den isuak,

den ndk nio anak kamanakan cucu atau katurunan lain dari den iduik

susah dikamudian hari,

tolong kau jago paliharo harato ko dih...

kok sia nan butuah dan susah ringan tangan lah kau manolong urang tu,

mudah-mudahan kamudian hari babaleh ka kau”,

Artinya harta saya tinggal untuk keturunan saya di kemudian hari agar tidak susah hidup nya di tengah-tengah masyarakt dan tidak di pandang sebelah mata oleh masyarkat kampunng atau Nagari, tolong dipelihara harta ini, kalaua ada yang butuh dan susah ringan tangan lah kamu untuk membantu meringkan beban mereka, mudah-mudahan di kemudian hari dibalas oleh Allah SWT. Mak hindun juga menyampaikan kepada anak cucu beliau bahwasanya harta kita sudah di gadaikan untuk keberlansungan hidup karena harta beliau di gagaikan untuk menyekolahkan anak, mambali baniah, membeli ternak, menggarap sawah, kebutuhan dapur sehari-hari serta untuk menikahkan anak beliau dan juga untuk memperbaiki rumah. Setahun sebelum beliau pergi untuk menghadap illahi beliau berpesan kepada cucu beliau:

"mak hindun: nak pai wak santa nah,

cucu: kama mak,

mak hindun: ka ateh pusaro urang sikumbang wak nah dakek kupalak,

cucu: jadih mak,

mak hindun: nak dari sawah ateh sampai bateh ka tapian banda musajik nagari tu sarato sawah nan disampiang rumah sarato diblakang rumah tu punyo awak yoh, dahulu amak gadaian untuk maamnuhi kabutuhan hiduik wak dahulu dek karano hiduik wak saisuaik susah, kok ado bisuak pitih tolong tabuih dih untuak adiak bisuak tu, soalnyo itu panando awak nan punyo sawah tu, itu pasan urang gaek wak saisuak, buliah di gadai tapi tolong balikan punyo wak tuliak alias tabuih,

cucu: insha allah mak, kok ado pitih kami cucu ko kami tabuih suak untuak katurunan awak kamudian hari,

mak hindun: aammin...ingek harato ko ndak ado hak di anak laki-laki do namun hanyo hak guno dan indak mamiliki sasuai jo adaik wak saisuak, sadonyo sapanuah nyo punyo cucu: jadih mak, adiak padusi,

mak hindun: amak lah jalehan samo si ati(anakperempuan) sawah ma se nan digadaian saisuak tu, namun saisuak tu wak lun mangarati jo ketentuan hukum lai, kok bisa kalian buek lah katantuan hukum namun kami katiko tu lah buek perjanjian hitam dia ateh putiah d saksikan jo tuo-tuo kampuang wak dahulu, 
cucu: jadih mak, bisuak ko wak caliak lah surek surek tu, mak hindun: jadih..

Harta kekayaan seperti hasil alam dan rumah dalam masyarakat Minangkabau diperoleh dari : (1) pusako, yaitu warisan adat/suku yang diketahui oleh kepala suku dan niniak mamak, alim ulama, cadiak pandai, (2) tembilang besi, yaitu hasil jerih payah sendiri, seperti membuka (manaruko) hutan untuk sawah dan ladang, (3) tambilang ameh (tembilang emas), yaitu memiliki harta dengan menggadai atau membeli dengan usaha sendiri dan (4) agiah (hibah), yaitu harta yang diberikan karena pemberian maksudnya harta yang didapat oleh orang yang mempunyai lahan yang luas namun bersifat kasihan atau iba terhadap orang tersebut dan keturunannya bertujuan untuk hidup layak di kemudian hari. Sistem penguasaan tanah di Nagari Jaho dapat dikategorikan menjadi empat macam yaitu : (1) lahan ulayat Nagari, yaitu lahan ulayat yang dimiliki Nagari yang digunakan untuk kepentingan Nagari (2) lahan ulayat suku, merupakan lahan ulayat yang digunakan secara perorangan oleh anggota suku secara bergantian dengan pengawasan berada di tangan penghulu suku, (3) lahan ulayat kaum, merupakan lahan ulayat yang dimiliki oleh suatu kaum, yang terdiri dari ladang dan sawah, tanah-tanah perumahan dan sekitarnya, dan (4) tanah hasil pencarian, yaitu tanah yang diperoleh dari hasil usaha sendiri (tambilang basi atau tambilang ameh).

\section{KESIMPULAN}

Bentuk Komunikasi yang dipakai di Nagari Jaho Kecamatan X Koto Kabupaten Tanah Datar tersebut menggunakan komunikasi secara langsung antar pribadi atau interpersonal decription sebagai alat untuk memperlancar maksud mereka, yaitu dengan bertatap muka secara langsung antara sipemagang dan sipenggadai atau tidak langsung dengan menggunakan surat-menyurat bertuliskan perjanjian pitih diganti pitih tabilang (uang diganti uang terbilang), tanah diganti tanah, sawah diganti sawah dan ameh (emas) diganti ameh (emas), untuk melakukan transaksi pagang gadai, karena sipemagang memberikan pinjaman ataupun uang untuk keperluan sipenggadai, adapun hal lain yang terjadi dalam melakukan pagang gadai di Nagari Jaho dengan memakai orang ketiga dalam melakukan transaksi pagang gadai. Dalam hal pagang gadai harus ada hal-hal sebagai berikut:

a. Membuat surat (tertulis) perjanjian pagang gadai (itam diateh putiah) dengan saksi-saksi yang lengkap dan diketahui oleh Niniak Mamak Penghulu kaum serta perangkat Nagari jaho Kecamatan X Koto Kabupaten Tanah Datar agar dikemudian hari tidak terjadi salah paham antar keturunan yang melakukan pagang gadai.

b. Memasukkan aspek waktu dalam perjanjian pagang gadai yang jelas beserta jihadnya (batas wilayah).

c. Sinergi/kolaboratif antara hukum adat dengan hukum positif Negara tidak tumpang tindih ke salah satu pihak.

d. Sinergi/kolaboratif antara hukum adat dan hukum pemerintahan agar tidak terjadi kekeliruan di kemudian hari

Hukum agama sangat berpengaruh dalam tatanan adat Minangkabau karena berfalsafah adat basandi sara', sara' basandi kitabullah. semua tatanan adat di Minangkabau umumnya dan khususnya Nagari Jaho berlandasakan Al-Qur'an dan Al-Hadist.

Masyarakat Nagari Jaho Kecamatan X Koto melakukan pagang gadai karena kebutuhan ekonomi yang mendesak yaitu kebutuhan sekolah anak, kebutuhan sehari-hari seperti kebutuhan dapur dan yang lainnya dan kebutuhan bertani (sawah dan ladang), aspek sosial budaya menjadi hal yang lumrah dalam melakukan pagang gadai. Kehidupan sosial budaya dan ekonomi di Nagari Jaho sampai saat ini sangat 
menjunjung adat istiadat dan mengutamakan musyawarah mufakat dalam hal apapun salah satunya dalam hal pagang gadai. untuk mendekatkan individu satu dengan individu lainnya. Adapun dalam hal pagang gadai juga dilakukan pendekatan secara lansung secara pribadi atau interpersonal descrption dan melakukan musyawarah mufakat dalam menyelesaikan pagang gadai antar kedua belah pihak

Hambatan komunikasi yang terjadi di Nagari Jaho yaitu sengketa/konflik dalam melakukan pagang gadai adalah keturunan pihak pertama dan pihak kedua tidak diikut sertakan dalam pagang gadai karena beralasan belum cukup umur, jadi akan diberitahukan pada saat umur \pm 17 Tahun dan juga mamak di dalam tatanan adat di Miangkabau khususnya Nagari Jaho tidak melakukan hal-hal yang diluar aturan adat yang ada sehingga menyusahkan keturunan yang ada, fungsi pokok mamak adalah sebagai pengawa harta pusako tinggi (pusaka tinggi) maupun pusako randah (pusako rendah). Penyelesaian sengketa/konnflik yang terjadi dengan cara musyawarah mufakat antar pihak sesuai dengan perjanjian yang telah ada dan yang sudah sampai ke meja hijau harus mengikuti sesuai hasil dari keputusan yang sudah di ambil secara hukum.

\section{SARAN}

Pagang gadai sawah yang dilakukan di Nagari Jaho masih jauh dari kata bagus, kurang memadai atau tidak terstruktur dengan baik dan banyak kekeliruan yang terjadi yang dilakukan niniak mamak yang mana kato adat basandi syara', syara' basandi kitabullah menjadi adat basandi siarak dimana penerus generasi nan tuo perlu memahami atau pun mendalami makna diatas agar tidak terjadi kekeliaruan atau kesalahan yang mendasar lagi. maka dari itu diberikan sebuah bentuk komunikasi agar tidak terjadi kekeliruan dikemudian hari pada Nagari Jaho. Dalam hal ini peneliti memberikan masukan tidak hanya di Nagari Jaho khususnya, namun umumnya juga di daerah-daerah admnistatif di Sumatera Barat. Semoga penelitian ini bermanfaat juga bagi Nagari-Nagari lain di Sumatera Barat dan umumnya bagi daerah lainnya di Indonesia.

Dalam tatanan pemerintahan Nagari dalam kasus pagang gadai ini, pemerintah Nagari harus menerapkan aturan yang tertulis agar tidak terjadi sengketa/konflik di Nagari Jaho, masyarakat Nagari Jaho harus dengan sadar melibatkan pemerintahan Nagari serta keturunan dalam melakukan pagang gadai agar dikemudian hari tidak terjadi sengketa/konflik yang berkepanjangan antara keturunan sipemagang dan si penggadai. Dalam hal kasus pagang gadai tanah/sawah pusako tinggi maupun pusako randah harus melibatkan struktur adat yang ada di Nagari Jaho dan menimilasirkan hal-hal yang tidak diinginkan agar tidak terjadi sengketa/konflik yang berkepanjangan di Nagari Jaho. Aspek ekonomi, sosial budaya di Nagari jaho sudah mengalami peningkatan namun adakalanya harus memperhatikan norma-norma yang ada agar tidak terjadi perselisihan yang berkepanjangan dan menyusahkan orang lain dan kembalikan fungsi sawah sebagai mana mestinya tidak digunakan untuk hal-hal yang tidak perlu. Dalam hal sosial budaya alangkah baiknya untuk mengurangi transaksi pagang gadai yang tidak perlu dalam kehidupan sehari-hari agar tidak terjadi kesenjangan sosial di Nagari Jaho. 


\section{DAFTAR PUSTAKA}

[1] Afifuddin dan S, B. A. 2009. Metodologi Penelitian Kualitatif. Pustaka Setia.

[2] Amriani, Nurnaningsih, Mediasi Alternatif Penyelesaian Sengketa Perdata Di Pengadilan. Jakarta: PT. Raja Grafindo Persada, 2012.

[3] Badan Pusat Statistik Kabupaten Tanah Datar, 2015. Luas Lahan Pertanian Kabupaten Tanah Datar.

[4] Bogdan dan Taylor, 1975 dalam J. Moleong, Lexy. 1989.Metodologi Penelitian Kualitatif. Bandung: Remadja Karya.

[5] Candra, 2016. Atasi Alih Fungsi Lahan, Sumbar Siapkan Perda Lahan Abadi untuk Pertanian. Bisnis.com diunggah pada tanggal 10 November 2016 pukul 08.30.

[6] Cangara, H, 2005, Pengantar Ilmu Komunikasi, Jakarta: PT RajaGrafindo Persada.

[7] Cangara, Hafied, Pengantar Ilmu Komunikasi (Rajawali Pers, Jakarta, 2012)

[8] DeFleur, M. L., and Sandra B-R (1982), Theories of Mass Communication. Longman, London.

[9] Departemen Pendidikan dan Kebudayaan RI, Kamus Besar Bahasa Indonesia, Cet III, Balai Pustaka, Jakarta, 1990 hlm 332.

[10]Haniva, 2008. Pelaksanaan Sistem Gadai Terhadap Tanah Ulayat Di Minangkabau (Studi kabupaten Padang Pariaman).

[11] Harsono, B. 2002. Menuju Penyempurnaan Hukum Tanah Nasional. Universitas Trisakti. Jakarta.

[12]Haar, Ter. Asas-Asas dan Susunan Hukum Adat, Terjemahan oleh K. Ng. Soebakti Poesponoto. Jakarta: Pradnya Paramita, 1980.

[13]Harjono, 2002. People, Poverty, and Livelihood: Links for Sustainable Poverty Reduction in Indonesia . Jakarta: The World Bank dan DFID.

[14]Imron, A. 2016. Riset Berbasis Kearifan Lokal Menuju Kemandirian Bangsa, http://aliimron.cv.unesa.ac.id, akses pada tanggal 2 November 2016, pukul 10.40 WIB. 